\title{
Estimation of Liquidus Temperature when SnAgCu BGA/CSP Components are Soldered with SnPb Paste
}

\author{
Jianbiao Pan, Ph.D., Assistant Professor \\ California Polytechnic State University \\ Department of Industrial and Manufacturing Engineering \\ San Luis Obispo, CA 93407, USA \\ Phone: (805) 756-2540 Fax: (805) 756-1420 \\ Email: pan@calpoly.edu
}

\begin{abstract}
Recently, the soldering of lead-free components with $\mathrm{SnPb}$ paste, or lead-free backward compatibility, is becoming a hot topic. One of the major challenges in backward compatibility assembly is the development of a right reflow profile for the soldering of $\mathrm{SnAgCu}$ Ball Grid Array (BGA)/Chip Scale Package (CSP) components with $\mathrm{SnPb}$ paste. If the $\mathrm{SnAgCu}$ reflow profile is used, the reflow temperature may be too high for other $\mathrm{SnPb}$ components in the same board during assembly according to the component rating per IPC/JEDEC J-STD-020C. In addition, the flux in $\mathrm{SnPb}$ solder paste may not function properly in such a high reflow temperature. On the other hand, if the $\mathrm{SnPb}$ reflow profile is used, $\mathrm{SnAgCu}$ solder ball may only partially melt. The incomplete mixing of the solder paste with the BGA/CSP ball raises serious reliability concern. Therefore, it is important to know the minimum reflow peak temperature that is able to achieve complete mixing of $\mathrm{SnPb}$ paste with leadfree components. This paper presents a method to estimate the liquidus temperature of mixed compositions when $\mathrm{SnAgCu}$ BGA/CSP components are soldered with $\mathrm{SnPb}$ paste. The liquidus temperature is the minimum reflow peak temperature able to achieve complete mixing of $\mathrm{SnPb}$ paste with lead-free components. It will be shown that the liquidus temperature depends on the $\mathrm{Pb}$ ratio in the mixed composition and the liquidus temperature is below $217^{\circ} \mathrm{C}$, which is the liquidus temperature of $\mathrm{SnAg} 3.0 \mathrm{Cu} 0.5$ solder. The liquidus temperatures of several experimental studies in literature are estimated and it is found that the estimated temperatures are consistent with experimental results. A user interface is designed using Visual Basic for Application in the Microsoft Excel environment to facilitate the estimation of the liquidus temperature. It is expected that the estimation of the mixed compositions liquidus temperature will be able to guide process engineers to develop a right reflow profile in backward compatibility assembly.
\end{abstract}

\section{Introduction}

In response to Europe's Restriction of Hazardous Substances (RoHS) and other countries' lead-free directives, the electronics industry is moving toward lead-free soldering. However, some products, such as servers, are exempt from the RoHS directive beyond 2010. Additionally products such as medical equipment, and military and aerospace products are not required to be lead-free. These products will continue to be built with conventional tin-lead $(\mathrm{SnPb})$ solder paste because the reliability of lead-free solder joints for these high reliability applications is still unknown. Since many component manufacturers are migrating to lead-free production, components such as memory modules are no longer available in $\mathrm{SnPb}$ finish. Therefore, soldering of leadfree components with $\mathrm{SnPb}$ paste, which is called backward compatibility, must be studied.

One of the major challenges in backward compatibility assembly is the development of the right reflow profile for the soldering of $\mathrm{SnAgCu}$ Ball Grid Array (BGA)/Chip Scale Package (CSP) components with $\mathrm{SnPb}$ paste. A schematic of the BGA/CSP backward compatibility assembly is shown in Figure 1. If the $\mathrm{SnAgCu}$ reflow profile (peak temperature of 230 to $250^{\circ} \mathrm{C}$ ) is used, the full mixing of the $\mathrm{SnPb}$ paste and the $\mathrm{SnAgCu}$ ball will be achieved as shown in Figure 2. But the reflow temperature may be too high for other $\mathrm{SnPb}$ components in the same board during assembly according to the component rating per IPC/JEDEC J-STD-020C. In addition, the flux in $\mathrm{SnPb}$ solder paste may not function properly at such a high reflow temperature. On the other hand, if the $\mathrm{SnPb}$ reflow profile is used, the $\mathrm{SnAgCu}$ solder ball will only partially melt and won't be self-aligned as shown in Figure 3. The incomplete mixing of the solder and no self-alignment of the BGA/CSP ball raise serious reliability concerns.

Studies [1-4] show that the reliability of solder interconnections degraded significantly when the $\mathrm{SnAgCu}$ ball is only partially mixed with the $\mathrm{SnPb}$ paste. Gregorich \& Holmes [1] reported that the reliability of backward compatibility assembly when the mixed assembly was reflowed at peak temperature of $200^{\circ} \mathrm{C}$ was much poorer than that of the control $\mathrm{SnAgCu}$ ball with $\mathrm{SnAgCu}$ paste in both the accelerated temperature cycling test from $-40^{\circ} \mathrm{C}$ to $+125^{\circ} \mathrm{C}$ and the mechanical shock test. The poor reliability is believed to be due to the inhomogeneous microstructure resulting from partial mixing of $\mathrm{Pb}$. The reliability of backward compatibility assembly improves as the reflow temperature increased to $225^{\circ} \mathrm{C}$. Hillman, et al. [2] evaluated the reliability of a $\mathrm{BGA}$ package assembled using a peak reflow temperature of $215^{\circ} \mathrm{C}$ with the duration of time above $200^{\circ} \mathrm{C}$ at 40 seconds. They observed partial mixing of $\mathrm{Pb}$ in the joint microstructure. The reliability of the solder joint was very poor as the solder joint failed at only 137 cycles in temperature cycling from $-55^{\circ} \mathrm{C}$ to $+125^{\circ} \mathrm{C}$ with dwell times of 11 minutes at each extreme and a ramp rate of $10^{\circ} \mathrm{C} /$ minute maximum per IPC-9701 guidelines. Hua, et al. [3-4] reported similar results showing that incomplete mixing lead to unacceptable solder joints. Therefore, it is critical to achieve 
complete mixing of $\mathrm{SnPb}$ paste with $\mathrm{SnAgCu}$ ball in BGA/CSP backward compatibility assembly.

The degree of mixing in backward compatibility assembly is expected to be a function of the reflow peak temperature and time above liquidus. Grossmann, et al. [5] observed that the $\mathrm{SnAgCu}$ ball was only partially mixed with $\mathrm{SnPb}$ paste at the reflow peak temperature of $210^{\circ} \mathrm{C}$; and the $\mathrm{SnAgCu}$ ball was totally dissolved when the reflow peak temperature exceeded $217^{\circ} \mathrm{C}$, which is the liquidus temperature of $\mathrm{Sn} 3.0 \mathrm{Ag} 0.5 \mathrm{Cu}$ alloy. They also found that a homogeneous reaction of the $\mathrm{SnPb}$ paste with the $\mathrm{SnAgCu}$ ball with a minimum formation of voids was achieved at the peak reflow temperature of about $230^{\circ} \mathrm{C}$. Zbrzezny, et al. [6] investigated various reflow profiles and concluded that complete mixing of the solders was achieved when the reflow peak temperature reached $218-222^{\circ} \mathrm{C}$.

Most of these studies believed that full mixing is achieved only when the reflow peak temperature exceeds $217^{\circ} \mathrm{C}$ [4-6], however, a full mixing of the $\mathrm{SnPb}$ paste with the $\mathrm{SnAgCu}$ ball can be achieved when the peak reflow temperature is below $217^{\circ} \mathrm{C}$. For example, Nandagopal, et al. [7-8] observed that a full mixing of the $\mathrm{SnPb}$ paste and the $\mathrm{SnAgCu}$ ball was accomplished at a peak reflow temperature of $210^{\circ} \mathrm{C}$ for about 15 to 25 seconds. They used the Differential Scanning Calorimeter (DSC) to characterize the time required to achieve full mixing. Handwerker [9] indicated that full mixing occurred at $207^{\circ} \mathrm{C}$ for sufficient time for a $\mathrm{Sn} 3.9 \mathrm{Ag} 0.6 \mathrm{Cu}$ solder ball constituting $75 \%$ of the final solder. Snugovsky, et al. [10] described the mixing process using a $\mathrm{SnPb}$ phase diagram. From the study, they concluded that a complete mixture may be achieved at a temperature lower than $217^{\circ} \mathrm{C}$ and that the temperature depends on solder ball composition, ball/solder paste ratio, dwell time, and component size.

Although a considerable amount of work [1-12] has been done so far on the backward compatibility assembly and its reliability, the minimum temperature able to achieve the full mixing is still unknown. The key in backward compatibility assembly is to develop a reflow profile with the peak temperature high enough to be able to achieve full mixing of the $\mathrm{SnPb}$ paste and the $\mathrm{SnAgCu}$ ball, and the peak temperature low enough (prefer below $220^{\circ} \mathrm{C}$ ) so that $\mathrm{SnPb}$ components won't be damaged. Therefore, it is critical to know the minimum reflow peak temperature that is capable of achieving a complete mixing of $\mathrm{SnPb}$ paste with lead-free components.

This paper presents an approach to estimate the mixed composition liquidus temperature when $\mathrm{SnAgCu}$ BGA/CSP components are soldered with $\mathrm{SnPb}$ paste. The mixed composition liquidus temperature is the minimum reflow peak temperature able to achieve complete mixing of $\mathrm{SnPb}$ paste with lead-free components. First, the calculation of mixed composition is described. Then the estimation of the liquidus temperature of the mixed composition is presented. The liquidus temperatures of different BGA/CSP component pitch levels are estimated. The liquidus temperatures of several experimental studies in published literatures are estimated as well, and it is found that the estimated liquidus temperatures are consistent with published experimental results. Finally, the paper describes a user interface designed to facilitate the estimation of liquidus temperature.

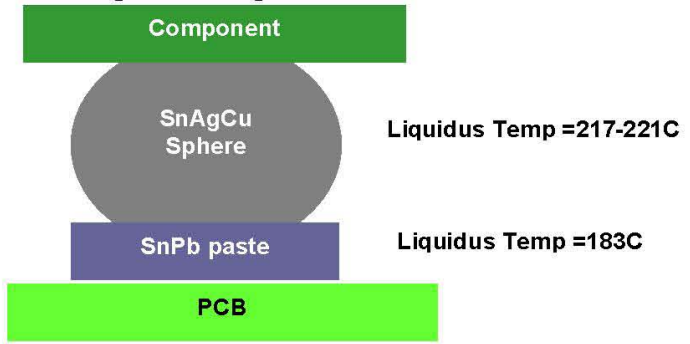

Figure 1. A schematic of BGA/CSP Backward Compatibility

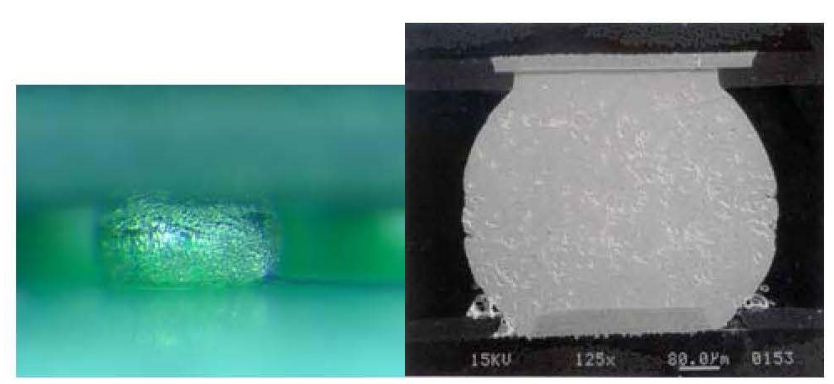

Figure 2. Full mixing achieved when the $\mathrm{SnAgCu}$ reflow profile is used

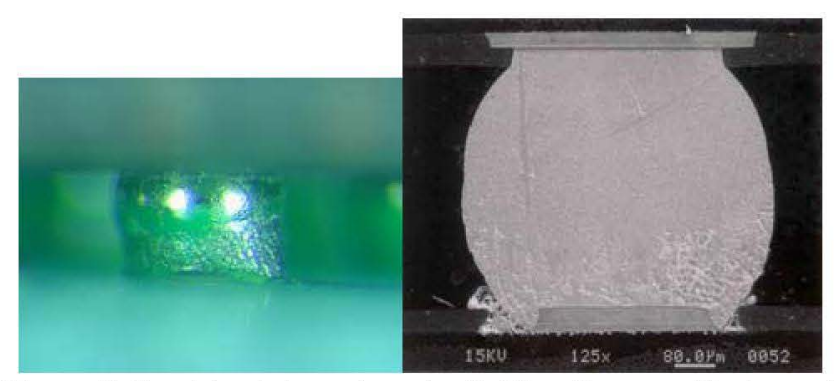

Figure 3. Partial mixing when the $\mathrm{SnPb}$ reflow profile is used

\section{Mixed Composition Calculation}

There are four alloying elements in the mixed composition when $\mathrm{SnAgCu} \mathrm{BGA} / \mathrm{CSP}$ components are soldered with $\mathrm{SnPb}$ paste: $\mathrm{Sn}, \mathrm{Ag}, \mathrm{Cu}$, and $\mathrm{Pb}$. The percentage of each metal element in the mixed composition can be calculated

$$
\begin{gathered}
W_{P b}=\frac{f_{P b} \times V_{\text {Paste }} \times f_{m} \times d_{\text {SnPb }}}{V_{\text {Paste }} \times f_{m} \times d_{\text {SnPb }}+V_{\text {Ball }} \times d_{\text {SnAgCu }}} \\
W_{\text {Ag }}=\frac{f_{A g} \times V_{\text {Ball }} \times d_{\text {SnAgCu }}}{V_{\text {Paste }} \times f_{m} \times d_{S n P b}+V_{\text {Ball }} \times d_{\text {SnAgCu }}} \\
W_{C u}=\frac{f_{C u} \times V_{\text {Ball }} \times d_{\text {SnAgCu }}}{V_{\text {Paste }} \times f_{m} \times d_{\text {SnPb }}+V_{\text {Ball }} \times d_{\text {SnAgCu}}} \\
W_{\text {Sn }}=100-\mathrm{W}_{\mathrm{Pb}}-\mathrm{W}_{\mathrm{Ag}}-\mathrm{W}_{\mathrm{Cu}}
\end{gathered}
$$

where $W_{P b}, W_{A g}, W_{C u}$, and $W_{S n}$ are the weight percentage of $\mathrm{Pb}, \mathrm{Ag}, \mathrm{Cu}$, and $\mathrm{Sn}$ in the mixed compositions, respectively; $f_{P b}$ is the percentage of $\mathrm{Pb}$ in weight in $\mathrm{SnPb}$ 
solder paste; $f_{A g}$ and $f_{C u}$ are the weight percentage of $\mathrm{Ag}$ and $\mathrm{Cu}$ in $\mathrm{SnAgCu}$ alloy; $f_{m}$ is the volume percentage of metal content in $\mathrm{SnPb}$ solder paste; $d_{S n P b}$ and $d_{S n A g C u}$ are the density of $\mathrm{SnPb}$ and $\mathrm{SnAgCu}$ alloys. $V_{\text {paste }}$ is the $\mathrm{SnPb}$ solder paste volume, which can be calculated

$$
V_{\text {paste }}= \begin{cases}L^{2} H(T R) & \text { for square aperature } \\ \pi\left(\frac{D}{2}\right)^{2} H(T R) & \text { for round aperture }\end{cases}
$$

where $\mathrm{L}$ is stencil aperture length for square aperture, $\mathrm{H}$ is stencil thickness, D is stencil aperture diameter for round aperture, and TR is the transfer ratio, which is defined as the ratio of the volume of solder paste deposited to the volume of the aperture.

$V_{b a l l}$ is the volume of a solder ball in the BGA/CSP component. If the ball diameter, $\mathrm{D}$, is given, the ball volume can be calculated

$$
V_{\text {ball }}=\frac{4}{3} \pi\left(\frac{D}{2}\right)^{3}
$$

If the sphere is reflowed and the ball height, $\mathrm{H}$, and radius, $\mathrm{R}$, are given, the ball volume can be calculated

$$
V_{\text {ball }}=\frac{2}{3} \pi R^{3}-\pi R^{3}\left\lfloor\frac{1}{3}\left(\frac{H-R}{R}\right)^{3}-\left(\frac{H-R}{R}\right)\right\rfloor
$$

For eutectic $\mathrm{SnPb}$ solder paste, $f_{P b}$ is 37 and typical value of $f_{m}$ is 0.5 (or $50 \%$ ). For $\mathrm{Sn} 3.0 \mathrm{Ag} 0.5 \mathrm{Cu}$ solder alloy, $f_{A g}=3.0$ and $f_{C u}=0.5$. The density of eutectic $\mathrm{Sn} 37 \mathrm{~Pb}, d_{\mathrm{SnPb}}$, is $8.4 \mathrm{~g} / \mathrm{cm}^{3}$ and the density of Sn4.0Ag05, $d_{S n A g C u}$, is $7.394 \mathrm{~g} / \mathrm{cm}^{3}$ [14].

For example, a $1 \mathrm{~mm}$ pitch Xilinx fine-pitch BGA (FG676) package with a $0.61 \mathrm{~mm}$ (24 mil) $\mathrm{Sn} 3 \mathrm{Ag} 0.5 \mathrm{Cu}$ ball diameter is assembled with $\mathrm{Sn} 37 \mathrm{~Pb}$ paste. The solder paste is printed using a $0.127 \mathrm{~mm}(5 \mathrm{mil})$ stencil with a $0.457 \mathrm{~mm}$ (18 mil) diameter round aperture. The $\mathrm{SnPb}$ paste has $50 \%$ metal content in volume. Assume a $90 \%$ transfer ratio. Using Equation 6, we can calculate that the volume of the $\mathrm{Sn} 3 \mathrm{Ag} 0.5 \mathrm{Cu}$ ball is $0.118 \mathrm{~mm}^{3}\left(7235 \mathrm{mil}^{3}\right)$. Using Equation 5, we can calculate the volume of $\mathrm{SnPb}$ paste is $0.0188 \mathrm{~mm}^{3}$ $\left(1125 \mathrm{mil}^{3}\right)$. Using Equations 1 to 4, we can get the final mixed alloy composition:

$$
\begin{aligned}
& W_{P b}=\frac{37 \times 0.0188 \times 0.5 \times 8.4}{0.0188 \times 0.5 \times 8.4+0.118 \times 7.394}=3.07 \\
& W_{A g}=\frac{3.0 \times 0.118 \times 7.394}{0.0188 \times 0.5 \times 8.4+0.118 \times 7.394}=2.75 \\
& W_{C u}=\frac{0.5 \times 0.118 \times 7.394}{0.0188 \times 0.5 \times 8.4+0.118 \times 7.394}=0.46 \\
& W_{S n}=100-3.07-2.75-0.46=93.7
\end{aligned}
$$

Therefore, the mixed composition is $93.7 \% \mathrm{Sn}, 3.1 \% \mathrm{~Pb}$, $2.8 \% \mathrm{Ag}$, and $0.5 \% \mathrm{Cu}$, all in weight.

\section{Estimation of Mixed Composition Liquidus Temperature}

After we know the mixed compositions, the next question becomes what is the liquidus temperature of mixed composition $\mathrm{Sn} 3.1 \mathrm{~Pb} 2.8 \mathrm{Ag} 0.5 \mathrm{Cu}$. The phase diagram of common binary and ternary systems that are relevant to solders can be obtained from the National Institute of Standards and Technology (NIST) webpage (available at http://www.metallurgy.nist. gov/phase/solder/solder.html). But the phase diagram of the complex quaternary $\mathrm{SnPbAgCu}$ is currently not available. The phase equilibria can be calculated from thermodynamic databases using the CALPHAD method [15]. Thermodynamic calculation is a very useful tool in obtaining phase diagram information, but it requires reliable thermodynamic databases and specialized knowledge. In this paper, the liquidus temperature of ternary and quaternary systems is estimated using the simple linearization of the binary liquidus lines. The linearization method has been successfully used by the National Institute of Standards and Technology (NIST) since the National Center for Manufacturing Sciences (NCMS) lead-free study [16]. Thus, the liquidus temperature of the quaternary $\mathrm{SnPbAgCu}$ system, a typical alloy system in backward compatibility assembly, can be calculated

$$
T_{l}=232^{\circ} \mathrm{C}-3.1 W_{A g}-7.9 W_{C u}-1.3 W_{P b}
$$

with limits: $\mathrm{W}_{\mathrm{Ag}}<3.5 ; \mathrm{W}_{\mathrm{Cu}}<0.7 ; \mathrm{W}_{\mathrm{Pb}}<38$; where $T_{l}$ is the liquidus temperature of Sn-rich solder alloys; 232 is the liquidus temperature of $\mathrm{Sn} ; \mathrm{W}_{\mathrm{Ag}}, \mathrm{W}_{\mathrm{Cu}}$, and $\mathrm{W}_{\mathrm{Pb}}$ are the percentage in weight of $\mathrm{Ag}, \mathrm{Cu}$, and $\mathrm{Pb}$, respectively. The coefficients before these alloy elements are the slope of the binary liquidus lines. For example, 1.3 is the slope of $\mathrm{SnPb}$ binary liquidus lines when $\mathrm{Pb}$ is less than $38 \%$ in weight; 7.9 is the slope of $\mathrm{SnCu}$ binary liquidus lines when $\mathrm{Cu}$ is less than $0.7 \%$ in weight; and so on. It should be emphasized that the limitation of the simple linearization is $\mathrm{W}_{\mathrm{Ag}}<3.5, \mathrm{~W}_{\mathrm{Cu}}<0.7$, and $\mathrm{W}_{\mathrm{Pb}}<38$. It should also be noted that Equation 8 is an approximation.

Based on Equation 8, the liquidus temperature of Sn3.0Ag0. $5 \mathrm{Cu}$,

$T_{l}=232^{\circ} \mathrm{C}-3.1 \times 3.0-7.9 \times 0.5-1.3 \times 0=219^{\circ} \mathrm{C}$

If $\mathrm{Ag}$ content is over $3.5 \%$ and less than $4 \% \mathrm{wt}, \mathrm{Ag}_{3} \mathrm{Sn}$ is primary phase. In this case, Equation 8 is not valid. A simple fix is to add $5^{\circ} \mathrm{C}$ to Equation 8 . Thus, the liquidus temperature of $\mathrm{Sn} 3.8 \mathrm{Ag} 0.7 \mathrm{Cu}$ is $T_{l}=232^{\circ} \mathrm{C}-3.1 \times 3.8-7.9 \times 0.7-1.3 \times 0+5=220^{\circ} \mathrm{C}$

Currently the reflow profiles in backward compatibility assembly are developed through costly trial-and-error method. It is expected that the estimation of the mixed compositions liquidus temperature will be able to guide process engineers to develop the right reflow profile in backward compatibility assembly.

Table 1 summarizes the final joint compositions and liquidus temperature with $\mathrm{Sn} 3 \mathrm{Ag} 0.5 \mathrm{Cu}$ (SAC305) ball and $\mathrm{Sn} 37 \mathrm{~Pb}$ paste for typical BGA/CSP component pitch levels. The aperture size, shape, stencil thickness and ball diameter are based on Solectron's guideline for no-clean paste. The transfer ratio is assumed based on experiences. It shows that the final liquidus temperature is lower than $217^{\circ} \mathrm{C}$, the liquidus temperature of $\mathrm{SAC} 305$. The liquidus temperature can be as low as $203^{\circ} \mathrm{C}$. As the pitch level decreases (except $0.5 \mathrm{~mm}$ pitch), the weight percentage of $\mathrm{Pb}$ increases and the liquidus temperature decreases. Equations 1 to 4 imply that 
the liquidus temperature depends on the ratio of BGA ball volume and solder paste volume.

Table 1. Final Joint Compositions and Liquidus Temperature with Sn3.0Ag0.5Cu Ball and Sn37Pb Paste

\begin{tabular}{|l|c|c|c|c|c|}
\hline Pitch (mm) & 1.27 & 1.0 & 0.8 & 0.65 & 0.5 \\
\hline $\begin{array}{l}\text { Aperture } \\
\text { size in mm } \\
\text { (mil) }\end{array}$ & $\begin{array}{c}0.533 \\
(21)\end{array}$ & $\begin{array}{c}0.457 \\
(18)\end{array}$ & $\begin{array}{c}0.406 \\
(16)\end{array}$ & $\begin{array}{c}0.356 \\
(14)\end{array}$ & $\begin{array}{c}0.279 \\
(11)\end{array}$ \\
\hline $\begin{array}{l}\text { Aperture } \\
\text { shape }\end{array}$ & Round & Square & Square & Square & Square \\
\hline $\begin{array}{l}\text { Stencil } \\
\text { thickness in } \\
\text { mm (mil) }\end{array}$ & $\begin{array}{c}0.152 \\
(6)\end{array}$ & $\begin{array}{c}0.127 \\
(5)\end{array}$ & $\begin{array}{c}0.127 \\
(5)\end{array}$ & $\begin{array}{c}0.127 \\
(5)\end{array}$ & $\begin{array}{c}1.02 \\
(4)\end{array}$ \\
\hline $\begin{array}{l}\text { Transfer } \\
\text { ratio (\%) }\end{array}$ & 100 & 90 & 85 & 80 & 70 \\
\hline $\begin{array}{l}\text { Ball } \\
\text { diameter } \\
\text { (mil) }\end{array}$ & 28 & 22 & 14 & 10 & 10 \\
\hline$\%$ of Pb & 3.4 & 4.8 & 11.1 & 17.0 & 11.7 \\
\hline$\%$ of $\mathrm{Ag}$ & 2.7 & 2.6 & 2.1 & 1.6 & 2.1 \\
\hline$\%$ of $\mathrm{Cu}$ & 0.5 & 0.4 & 0.3 & 0.3 & 0.3 \\
\hline $\begin{array}{l}\text { Estimated } \\
\text { liquidus } \\
\text { temp. }\left({ }^{\circ} \mathrm{C}\right)\end{array}$ & 216 & 214 & 208 & 203 & 208 \\
\hline
\end{tabular}

Equation 8 shows that a higher $\mathrm{Pb}$ percentage in the mixed compositions can reduce the mixed composition liquidus temperature. The higher $\mathrm{Pb}$ percentage can be achieved by printing more $\mathrm{SnPb}$ solder paste or reducing the $\mathrm{SnAgCu}$ solder ball. But it is unclear what effect of high $\mathrm{Pb}$ content in mixed compositions on the backward compatibility reliability. $\mathrm{Zhu}$, et al. [17] studied the effect of $\mathrm{Pb}$ contamination on the lead-free solder joint microstructure and observed a $\mathrm{Pb}$-rich phase formed in the bulk solder when the lead-free solder contains $\mathrm{Pb}$ impurity. Zeng [18] discussed the influence of the $\mathrm{Pb}$-rich phase on solder joint reliability. The $\mathrm{Pb}$-rich phase may be the weakest region in the bulk solder, and the crack may propagate along the $\mathrm{Pb}$-rich phase interface during reliability testing $[17,18]$. Bath, et al. [11] found that the reliability of backward compatibility assembly in accelerated temperature cycling (ATC) from $0^{\circ} \mathrm{C}$ to $100^{\circ} \mathrm{C}$ with 40 minute a cycle, even when the full mixing was achieved, was poorer than that of both $\mathrm{SnAgCu}$ ball/ $\mathrm{SnAgCu}$ paste and $\mathrm{SnPb}$ ball/ $\mathrm{SnPb}$ paste. But Bandagopal, et al. [7] found that the reliability of backward compatibility assembly in both ATC from $0^{\circ} \mathrm{C}$ to $100^{\circ} \mathrm{C}$ and $-40^{\circ} \mathrm{C}$ to $125^{\circ} \mathrm{C}$ was better than the $\mathrm{SnPb}$ assembly when the full mixing was achieved. Furthermore, the reliability data of $\mathrm{SnPb} \mathrm{BGA}$ ball soldered with $\mathrm{SnAgCu}$ paste (or forward compatibility), where high $\mathrm{Pb}$ content is in the mixed compositions, was better or equal to that of $\mathrm{SnPb}$ ball/ $\mathrm{SnPb}$ paste control assemblies [19]. Therefore, no conclusion can be drawn yet regarding what effect of $\mathrm{Pb}$ content has on the backward compatibility reliability.

To assess the method, we estimated the liquidus temperatures from published experimental studies and compared the estimated liquidus temperature with published experimental results. The estimated temperatures and the published experimental results are summarized in Table 2. If the reflow peak temperature used is higher than the estimated liquidus temperature, full mixing is expected. Otherwise, partial mixing is expected. Overall, Table 2 shows that the estimated liquidus temperatures are consistent with reported experimental results. There are small variances between the estimated temperature and the reported results of studies in references 7 and 11. This could be due to the inaccuracy transfer ratio assumptions. Since only a few studies have reflow peak temperatures close to the estimated liquidus temperature, further experimental study is needed to validate the accuracy of the estimation method.

Table 2. Comparison of the estimated Liquidus Temperature and the Reported Experimental Results

\begin{tabular}{|c|c|c|c|}
\hline Reference & $\begin{array}{c}\text { Estimated } \\
\text { liquidus } \\
\text { temperature }\end{array}$ & $\begin{array}{c}\text { Peak reflow } \\
\text { temperature } \\
\text { used }\end{array}$ & $\begin{array}{c}\text { Experimental } \\
\text { results }\end{array}$ \\
\hline $\begin{array}{c}\text { Gregorich \& } \\
\text { Holmes [1] }\end{array}$ & $209^{\circ} \mathrm{C}$ & $200^{\circ} \mathrm{C}$ & Partial mixing \\
\cline { 3 - 4 } & & $225^{\circ} \mathrm{C}$ & Full mixing \\
\hline $\begin{array}{c}\text { Hillman, et } \\
\text { al. [2] }\end{array}$ & $219^{\circ} \mathrm{C}$ & $215^{\circ} \mathrm{C}$ & Partial mixing \\
\hline $\begin{array}{c}\text { Grossmann, } \\
\text { et al. [5] }\end{array}$ & $216^{\circ} \mathrm{C}$ & $210^{\circ} \mathrm{C}$ & Partial mixing \\
\cline { 3 - 4 } $\begin{array}{c}\text { Nandagopal, } \\
\text { et al. [7] }\end{array}$ & $212^{\circ} \mathrm{C}$ & $217^{\circ} \mathrm{C}$ & Full mixing \\
\hline Bath, et al. & $210^{\circ} \mathrm{C}$ & $227^{\circ} \mathrm{C}$ & Full mixing \\
\cline { 3 - 4 } [11] & $205^{\circ} \mathrm{C}$ & Full mixing \\
\cline { 3 - 4 } & & $214^{\circ} \mathrm{C}$ & Furtial mixing mixing \\
\hline
\end{tabular}

\section{User Interface Development}

To facilitate the estimation of the mixed composition liquidus temperature, a user interface was developed using Visual Basic for Application in the Microsoft Excel environment. Focus has been on designing an easy-tounderstand user interface. One major feature with the user interface is that the input data, control menu and the results are presented on the same page. Another feature is that default data from typical assembly guidelines will be shown when a user selects a package pitch level. The user is also allowed to manipulate all input data. The input parameters include package pitch, package solder ball type, stencil dimensions, and solder paste compositions. The output data include mixed compositions, solder paste volume, and the estimated liquidus temperature. Figure 4 shows the interface for the $\mathrm{BGA} / \mathrm{CSP}$ component user form.

\section{Summary}

A method to estimate the mixed composition liquidus temperature when lead-free components are soldered with tinlead solder paste was presented. The estimated liquidus temperatures of published experimental studies are consistent with reported experimental results.

The liquidus temperature of backward compatibility assembly is lower than that of $\mathrm{SnAgCu}$ alloy. The temperature depends on the ratio of $\mathrm{Pb}$ in the mixed compositions. The ratio of $\mathrm{Pb}$ is influenced by the BGA ball volume, ball solder alloy types, and solder paste volume. Generally speaking, the smaller the pitch level of BGA/CSP components, the higher weight percentage of $\mathrm{Pb}$, thus the lower the liquidus 
temperature. But the effect of high $\mathrm{Pb}$ content on the reliability of backward compatibility assemblies is still unclear.

A user interface for the liquidus temperature estimation was designed using Visual Basic for Application in the Microsoft Excel environment.

It is expected that the estimation of the mixed compositions liquidus temperature will be able to guide process engineers to develop the right reflow profile in backward compatibility assembly
Future experimental study is needed to confirm the accuracy of the estimation method for liquidus temperature of mixed compositions.

\section{Acknowledgments}

The author would like to express his gratitude to the Solectron Corporation, Milpitas, CA, for technical and financial support; to Kim Hyland, Dennis Willie, and Jasbir Bath, without whom this work would not have been possible. The author would like to thank Nick Benigno for the implementation of the user interface.

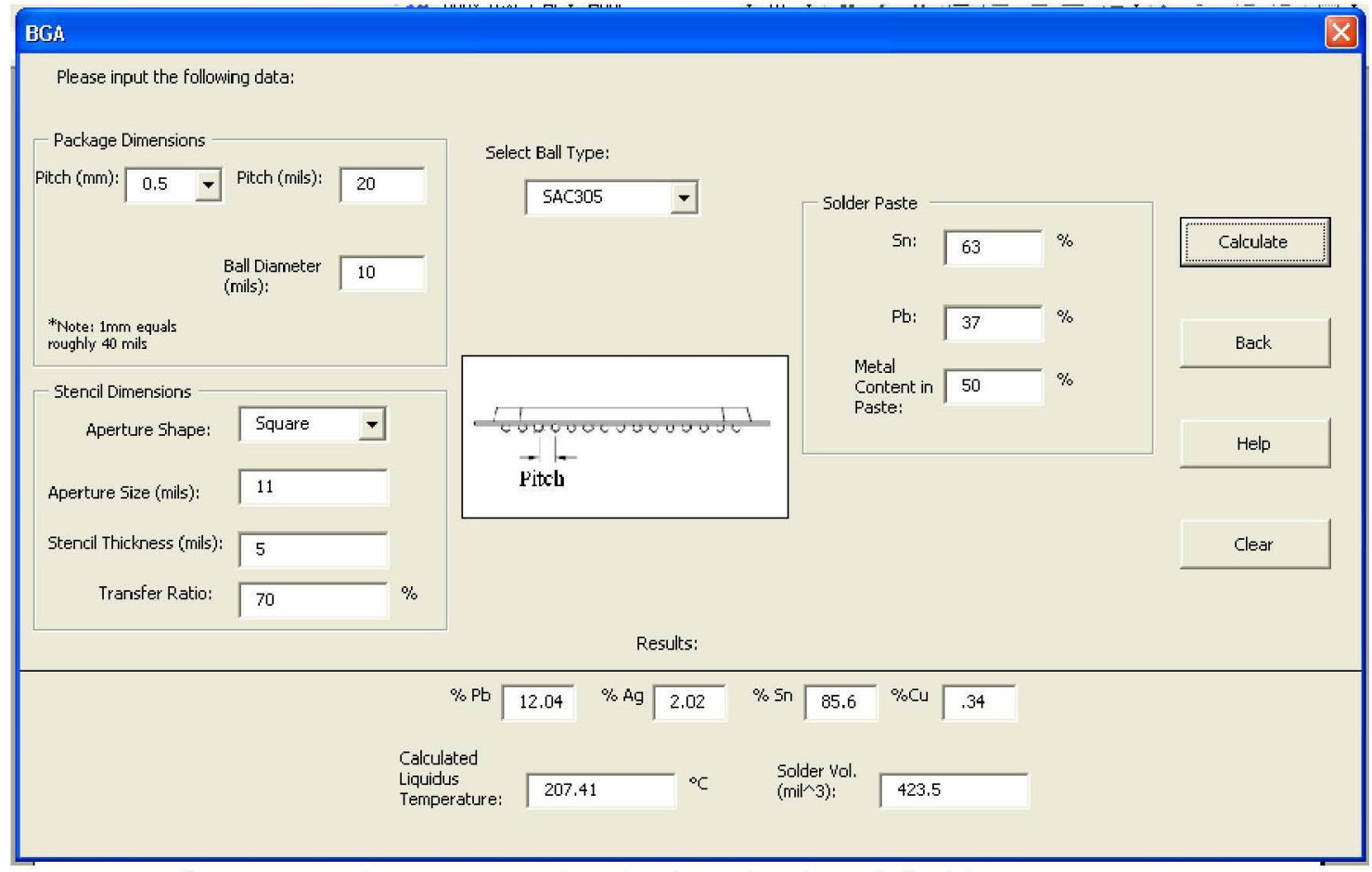

Figure 4. BGA/CSP User Interface for the Estimation of Liquidus Temperature

\section{References}

1. Gregorich T. \& Holmes P. Low-Temperature, High Reliability Assembly of Lead-free CSPS, IPC/JEDEC 4th International Conference on Lead-free Electronic Components and Assemblies, Frankfurt, Germany, 2003.

2. Hillman D., Wells $\mathrm{M}_{\text {, }}$, and Cho K. The Impact of Reflowing a Pb free Solder Alloy Using a Tin/Lead Solder Alloy Reflow Profile on Solder Joint Integrity, International Conference on Lead-free Soldering, CMAP, Toronto, Canada, May 24-26, 2005

3. Hua F, Aspandiar R., Rothman T., Anderson C., Clemons G., and Klier M. Solder Joint Reliability of Sn-Ag-Cu BGA Components Attached with Eutectic Pb-Sn Solder Pate, Journal of Surface Mount Technology, 2003, 16 (1) $34-42$.

4. Hua F, Aspandiar R., Anderson C., Clemons G., Chung C., and Faizul, M. Solder Joint Reliability Assessment of Sn$\mathrm{Ag}-\mathrm{Cu}$ BGA Components Attached with Eutectic Pb-Sn Solder, SMTA International, Chicago, IL, pp. 246-252.

5. Grossmann G., Tharian J., Jud P. and Sennhauser U. Microstructural investigation of lead-free BGAs soldered with tin-lead solder, Soldering \& Surface Mount Technology, 2005: 17 (2), 10-21.

6. Zbrzezny AR, Snugovsky $\mathrm{P}$, Lindsay $\mathrm{T}$, and Lau $\mathrm{R}$. Reliability Investigation of $\mathrm{Sn}-\mathrm{Ag}-\mathrm{Cu}$ BGA Memory Modules Assembled with $\mathrm{Sn}-\mathrm{Pb}$ Eutectic Paste Using Different Reflow Profiles, International Conference on Lead-free Soldering, CMAP, Toronto, Canada, May 24-26, 2005.

7. Nandagopal B., Mei Z., and Teng S. Microstructure and Thermal Fatigue Life of BGAs with Eutectic Sn-Ag-Cu Balls Assembled at $210^{\circ} \mathrm{C}$ with Eutectic Sn-Pb Solder Paste, Proceedings of 2006 IEEE Electronic Components and Technology Conference, San Diego, CA, 2006: 875883.

8. Nandagopal B., Chiang D., Teng S., Thune P., Anderson L., Jay R. and Bath J. Study on Assembly, Rework, Microstructures and Mechanical Strength of Backward Compatible Assembly, Proceedings of 2005 SMTA International, Chicago, IL, 2005: 861-870.

9. Handwerker C. Transitioning to Lead Free Assemblies, Printed Circuit Design and Manufacturing, March 2005: $17-23$. 
10. Snugovsky P., Zbrzezny AR, Kelly M, and Romansky M. Theory and Practice of Lead-free BGA Assembly using $\mathrm{Sn}-\mathrm{Pb}$ Solder, International Conference on Lead-free Soldering, CMAP, Toronto, Canada, May 24-26, 2005.

11. Bath J, Sethuraman S, Zhou X, Willie D, Hyland K, Newman K, Hu L, Love D, Reynolds H, Kochi K, Chiang D, Chin V, Teng S, Ahmed M, Henshall G, Schroeder V, Nguyen Q, Maheswari A, Lee MJ, Clech J-P, Cannis J, Lau J, Gibson C. Reliability Evaluation of Lead-free SnAgCu PBGA676 Components using Tin-Lead and Lead-free $\mathrm{SnAgCu}$ solder paste, Proceedings of 2005 SMTA International, Chicago, IL, 2005: 891-901.

12. Theuss H, Kilger T, and Ort T. Solder Joint Reliability of Lead-Free Solder Balls Assembled with SnPb Solder Paste, Proceedings of 2003 IEEE Electronic Components and Technology Conference, New Orleans, LA, 2003: 331-337.

13.Pan J and Bath J. Lead Free Soldering Backward Compatibility, IPC/JEDEC 12th International Conference on Lead Free Electronic Components and Assemblies, Santa Clara, CA, March 7-9, 2006.

14. Siewert T, Liu S, Smith DR, Madeni JC. Database for solder properties with emphasis on new lead-free solders. NIST \& Colorado School of Mines, Release 4.0, Feb. 2002 ,

http://www.boulder.nist.gov/div853/lead free/solders.html

15. Kattner UR. and Handwerker CA. Calculation of Phase Equilibria in Candidate Solder Alloys, Z. Metallkd. 92 (2001): $1-10$.

16. Kattner UR. and Handwerker CA. personal communication though emails, 2005.

17.Zhu Q, Sheng $\mathrm{M}$, and Luo $\mathrm{L}$. The effect of $\mathrm{Pb}$ contamination on the microstructure and mechanical properties of $\mathrm{SnAg} / \mathrm{Cu}$ and $\mathrm{SnSb} / \mathrm{Cu}$ solder joints in $\mathrm{SMT}$, Soldering and Surface Mount Technology, 12 (3), 2000: 19-23.

18.Zeng $\mathrm{X}$. Thermodynamic analysis of influence of $\mathrm{Pb}$ contamination on $\mathrm{Pb}$-free solder joint reliability, Journal of Alloys and Compounds, 348 (2005): 184-188.

19. Handwerker CA, Bath J, Benedetto E, Bradley E, Gedney R, Siewert T, Snugovsky P, and Sohn J. NEMI Lead-free Assembly Project: Comparision Between PbSn and SnAgCu Reliability and Microstructure, Proceedings of SMTA International, 2003. 